\title{
AMATL: Galería Colaborativa para la conservación y difusión de fotografías digitales de Teotitlán de Flores Magón, Oaxaca
}

\section{AMATL: Collaborative Gallery for conservation and diffusion of photographs of Teotitlán de Flores Magón, Oaxaca}

\author{
LÓPEZ-ANTONIO, Gilberto†, SABINO-MOXO, Beatriz Adriana* y MARQUEZ-DOMINGUEZ, José \\ Alberto
}

Universidad de la Cañada

ID $1^{\text {er }}$ Autor: Gilberto, López-Antonio/ ORC ID: 0000-0002-8623-7564, CVU CONACYT ID: 1003107

ID $1^{\text {er }}$ Coautor: Beatriz Adriana, Sabino-Moxo / ORC ID: 0000-0002-8577-494X, CVU CONACYT ID: 210495

ID $2^{\text {do }}$ Coautor: José Alberto, Márquez-Domínguez / ORC ID: 0000-0003-2552-2289, CVU CONACYT ID: 210472

DOI: $10.35429 /$ JCT.2019.10.3.17.22

Recibido 18 de Julio, 2019, Aceptado, 02 de Septiembre, 2019

\begin{abstract}
Resumen
La fotografía es un documento que refleja un testimonio visual de acontecimientos políticos, científicos, sociales y culturales de la humanidad, juega un papel importante en la conservación, transmisión y visualización de dichos sucesos. En este trabajo se presenta el diseño e implementación de una galería que permite generar una colección fotográfica de Teotitlán de Flores Magón a partir de la contribución de sus habitantes. El objetivo de esta aplicación es rememorar y mostrar el pasado a las nuevas generaciones a través de una memoria colectiva basada en fotografía. El desarrollo del software se realizó empleando el lenguaje PHP, el manejador de base de datos MySQL y el modelo vista-controlador que permite una mejor organización del código de la aplicación, lo que facilita a los desarrolladores el mantenimiento y actualización de ésta. La metodología del proceso evolutivo fue empleada en este proyecto, por lo que se llevaron a cabo dos iteraciones para obtener un mejor software. La evaluación de la usabilidad realizada a varios usuarios que interactuaron con la galería colaborativa mostró resultados favorables con respecto a las métricas satisfacción, eficiencia y eficacia.
\end{abstract}

Modelo vista-controlador, Aplicación web, Usabilidad

\begin{abstract}
Photography is a document that reflects a visual testimony of political, scientific, social and cultural events of humanity, plays an important role in the conservation, transmission and visualization of such events. This work presents the design and implementation of a gallery to generate photographic collection of Teotitlán de Flores Magón through the collaboration of the population. The objective of this application is to remember and show the past to the new generations through a collective memory based on photography. The development of the software was done using the PHP language, the MySQL database manager and the view-controller model that allows a better organization of the application code, which facilitates the maintenance and updating of the application by the developers. The evolutionary process methodology was used in this project, all its stages were carried out to obtain a better software. The evaluation of usability with several users showed beneficial results with respect to satisfaction, efficiency and effectiveness metrics.
\end{abstract}

View-controller model, Web application, Usability

Citación: LÓPEZ-ANTONIO, Gilberto, SABINO-MOXO, Beatriz Adriana y MARQUEZ-DOMINGUEZ, José Alberto. AMATL: Galería Colaborativa para la conservación y difusión de fotografías digitales de Teotitlán de Flores Magón, Oaxaca. Revista de Tecnología Informática. 2019 3-10: 17-22

\footnotetext{
* Correspondencia del Autor (Correo electrónico: beatriz_sabino@unca.edu.mx)

$\dagger$ Investigador contribuyendo como primer autor.
} 


\section{Introducción}

La fotografía es un documento que refleja un testimonio visual de acontecimientos políticos científicos, sociales y culturales de la humanidad, juega un papel importante en la conservación, transmisión y visualización de dichos sucesos. Así mismo, son consideradas como testimonio del pasado, reflejo de vivencias y ocurrencias, estilo de vida, costumbres y tradiciones de la época.

La imagen fotográfica ha abierto una nueva vía de transmisión y conservación del conocimiento a través de imágenes, constituye uno de los patrimonios documentales que más se ha difundido y conforma la memoria visual de la sociedad (Batista, 2016). De igual modo, Saltos (2017) denomina a la fotografía como una fuente de datos que permite el acercamiento al pasado, en ésta se observa la captura de monumentos, calles, vestimentas, fiestas, modos de vida, etc. Por lo que es un patrimonio que merece ser conservado y apreciado, debido a su frágil condición y en que ocasiones es el único testimonio de un bien que ya no se encuentra en el presente o que fue modificado.

Los proyectos de recopilación de fotografías tienen como objetivo rememorar y mostrar el pasado a las nuevas generaciones a través de una memoria compartida o colectiva (ARSSI, 2016). Por lo que la colaboración de las personas juega un papel importante en la construcción de dicha memoria.

La galería colaborativa AMATL permite administrar, almacenar y manipular fotografías digitales de Teotitlán de Flores Magón, Oaxaca. Dicha aplicación coadyuvará en la conservación y difusión de la información histórica y cultural de Teotitlán de Flores Magón, Oaxaca. Cabe mencionar que esta investigación está respaldada por la casa de la Cultura de Teotitlán de Flores Magón, debido a que ellos tienen el interés de crear una colección fotográfica de esta comunidad.

\section{Galerías colaborativas}

Una galería colaborativa es un espacio en el que se exhiben fotografías o pinturas con la participación de una serie de colaboradores que se encargan de compartir dicho contenido con el público en general (Palacios, 2009).
AMATL (Significa papel en náhuatl) es una galería que permite a las personas de la localidad agregar fotografías digitales que quieran compartir, con la información adicional como: fecha, lugar, nombres de las personas que aparecen en ella, entre otros. Es importante resaltar, que el contenido del sistema es supervisado por el personal (administrador) de la casa de la cultura para asegurar la autenticidad de las fotografías y que el contenido corresponda a la temática de la galería.

Las imágenes aprobadas por el usuario administrador son accesibles por el público en general, a su vez permite que se pueda interactuar con el contenido realizando varias actividades.

García y otros (2015) comentan que uno de los principales aspectos que se consideran para valorar los contenidos en redes sociales, son las formas de interacción, por lo que en la tabla I se describen las principales características de AMATL y las formas de interacción que tendrá. Tabla 1. Características de AMATL.

\begin{tabular}{|c|c|}
\hline $\begin{array}{l}\text { Datos que } \\
\text { almacena }\end{array}$ & $\begin{array}{lccc}\text { Datos que } & \text { marca } & \text { la Norma } \\
\text { Mexicana } & \text { de } & \text { Documentos } \\
\text { Fotográficos } & (2016) . & \\
\end{array}$ \\
\hline $\begin{array}{l}\text { Formas de } \\
\text { interacción }\end{array}$ & $\begin{array}{l}\text { - Compartir en redes sociales } \\
\text { - Indicar "Me gusta" } \\
\text { - Hacer comentarios }\end{array}$ \\
\hline $\begin{array}{l}\text { Características } \\
\text { de los archivos } \\
\text { digitales }\end{array}$ & $\begin{array}{l}\text { - Se almacenan en diferentes } \\
\text { resoluciones } \\
\text { - La cantidad de fotografías } \\
\text { almacenadas es de acuerdo al } \\
\text { espacio de almacenamiento en el } \\
\text { servidor. }\end{array}$ \\
\hline Otras & $\begin{array}{l}\text { - Disponible al público en general. } \\
\text { - Código fuente disponible. }\end{array}$ \\
\hline
\end{tabular}

Además, las fotografías que se pueden agregar a la galería tienen las siguientes características:

- $\quad$ Fotografías en formato blanco y negro, escala de grises o color sepia.

- Fotografías que ilustran elementos que ya no están presentes físicamente en la comunidad.

- Fotografías que ilustran elementos que fueron modificados.

- Fotografías que ilustran eventos o actividades culturales, religiosas, deportivas, etc. que se realizaban anteriormente y que ahora ya no se practican. 
En la siguiente sección se describe la metodología empleada en este trabajo de investigación.

\section{Metodología}

Al trabajar en el desarrollo de software es importante ejecutar una serie de actividades para obtener en tiempo favorable un producto de calidad. Los modelos evolutivos son iterativos, se caracterizan por obtener una versión mejor en cada iteración.

El método de proceso evolutivo en el que nos centramos consiste en realizar prototipos, ya que de esta manera se pueden identificar requerimientos detallados para las características $\mathrm{y}$ funciones.

El paradigma de hacer prototipos favorece a la comprensión de lo que hay que hacer cuando los requerimientos no están claros. Es ideal que el prototipo sirva como mecanismo que permita detectar requerimientos de software que no fueron contemplados. La estructura general para la ingeniería de software define cinco actividades estructurales: Comunicación, Planeación, Modelado, Construcción y Despliegue (Pressman, 2010).

La importancia que tiene aplicar un proceso de desarrollo es porque brinda estabilidad, control y organización a la serie de actividades que se pueden salir de control. Se utilizó el flujo de proceso evolutivo debido a que se realizaron las actividades en forma circular, dónde cada circuito nos llevó a una versión más completa del software. En la Figura 1 se muestra el flujo de proceso evolutivo.

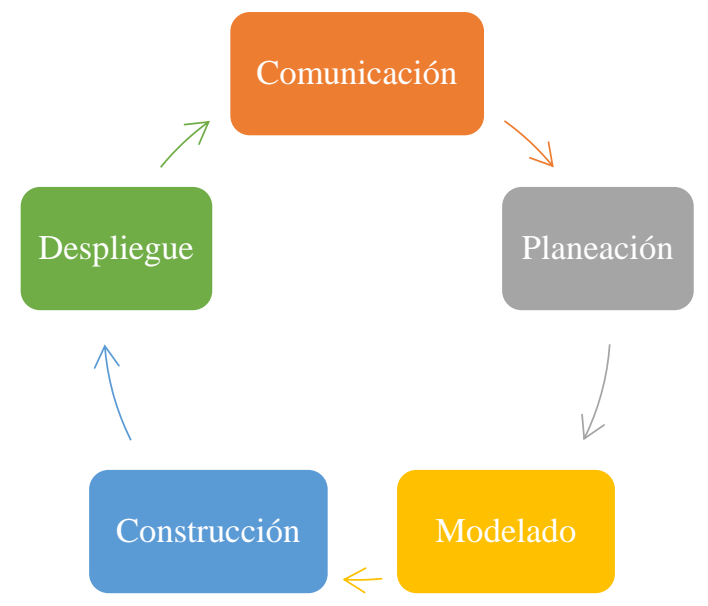

Figura 1 Flujo de proceso evolutivo
Comunicación. En esta sección, se tiene como objetivo general desarrollar una galería colaborativa para la conservación y difusión de fotografías digitales de Teotitlán de Flores Magón, Oaxaca. Para lograr este objetivo se realizaron las siguientes actividades:

- Análisis los requerimientos de software AMATL.

- Diseño del modelo de base de datos relacional que se administra y manipula con el software.

- $\quad$ Diseño de la arquitectura de la aplicación considerando el Modelo-VistaControlador.

- Implementación del software siguiendo el paradigma Orientado a Objetos.

- Evaluación la funcionalidad de la aplicación cuando esté alojado en un servidor.

Planeación. En esta etapa fue planeada una iteración para realizar un prototipo. Durante el desarrollo de AMATL se realizaron dos iteraciones, de las cuales se obtuvieron dos prototipos, como se puede ver en las Figuras 2 a 5 y Figuras 6 a 9 respectivamente.

Modelado. La primera tarea que se realizó en esta etapa fue el modelado de la base de datos ya que es la que nos permite almacenar, organizar y manipular la información. A continuación, se mencionan las entidades que se tomaron en cuenta para su diseño:

$\begin{array}{ll}- & \text { Imágenes } \\ - & \text { Usuarios } \\ - & \text { Comentarios } \\ - & \text { Comunidades } \\ - & \text { Lenguas }\end{array}$

A partir de este modelo de base de datos, los casos de uso que fueron considerados para la interacción con AMATL son los siguientes:

Usuarios en general:

- Ver la galería de imágenes.

- $\quad$ Registrarse en AMATL.

Usuario administrador:

- $\quad$ Iniciar sesión.

- Aprobar o rechazar fotografías.

- Dar de alta lenguas maternas.

LÓPEZ-ANTONIO, Gilberto, SABINO-MOXO, Beatriz Adriana y MARQUEZ-DOMINGUEZ, José Alberto. AMATL: Galería Colaborativa para la conservación y difusión de fotografías digitales de Teotitlán de Flores Magón, Oaxaca. Revista de Tecnología Informática. 2019 


\section{- $\quad$ Bloquear usuarios.}

Usuario colaborador:

- Iniciar sesión.

- Subir fotografías.

- Hacer comentarios.

- $\quad$ Indicar me gusta.

- Compartir en redes sociales.

Construcción. Los dos prototipos que se mencionaron anteriormente fueron implementados, siendo el último (Figura 6 a 9) una versión más completa que la anterior (Figura 2 a 5). Ya que es este se tomó en cuenta la Norma Mexicana de Documentos Fotográficos (2016) para el almacenamiento de metadatos de las fotografías.

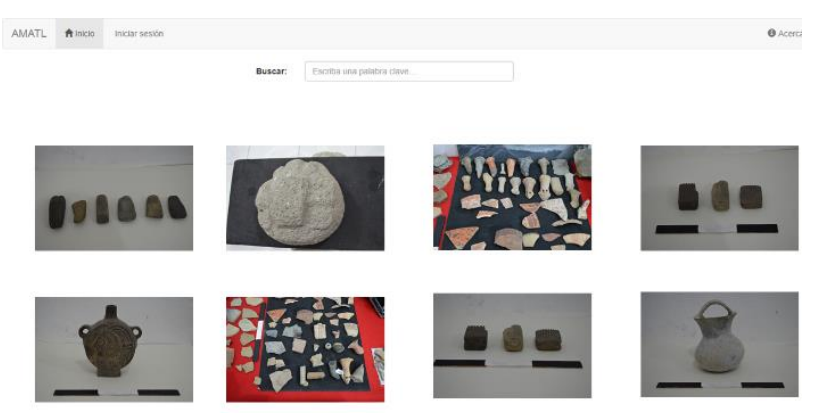

Figura 2 AMATL v1.0. Interfaz principal

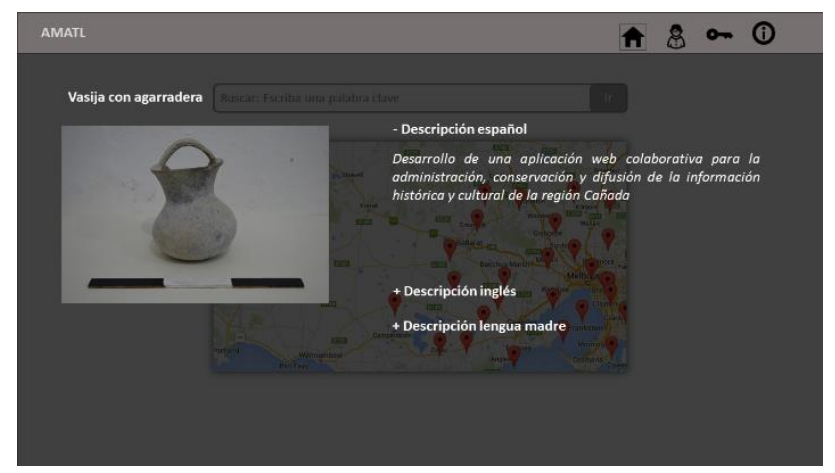

Figura 3 AMATL v1.0. Vista previa de fotografía

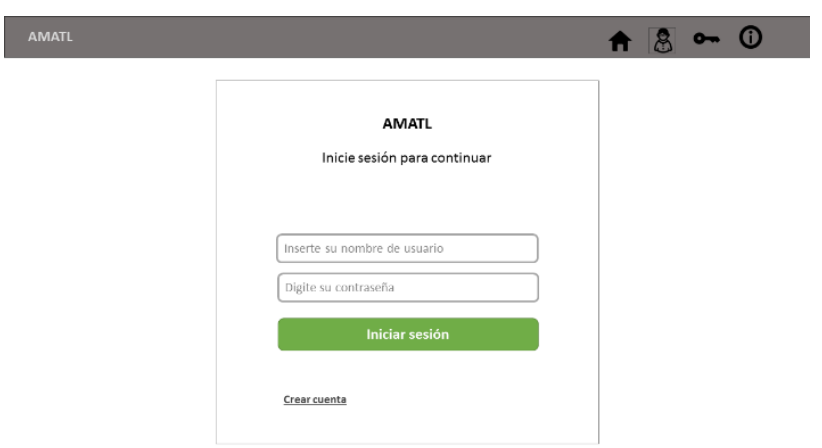

Figura 4 AMATL v1.0. Inicio de sesión

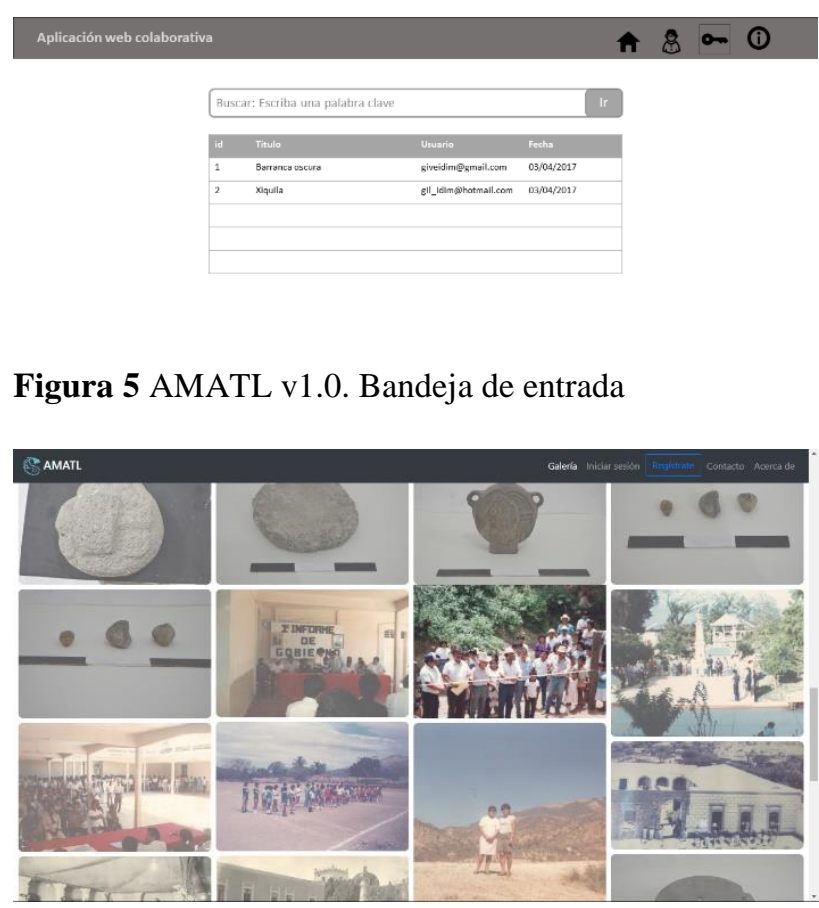

Figura 6 AMATL v2.0. Interfaz principal

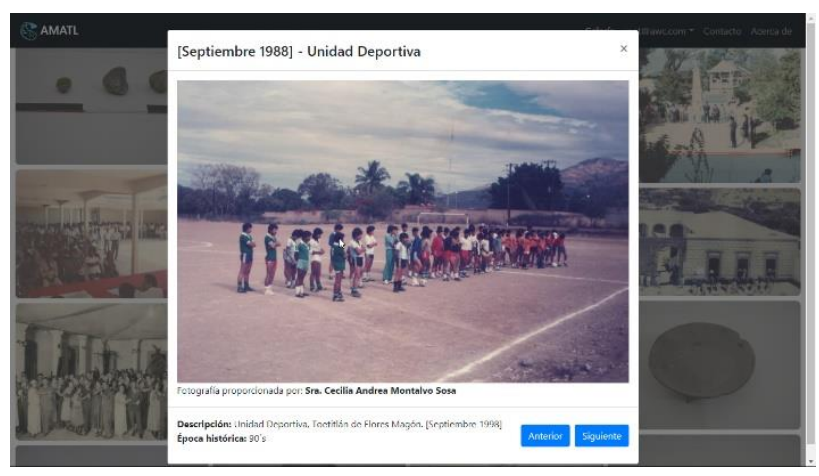

Figura 7 AMATL v1.0. Vista previa de fotografía

AMATL

Inicie sesión para acceder
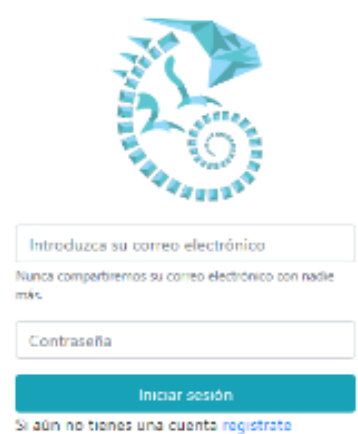

Sis sun no tianes uns cuente rogistrate

Figura 8 AMATL v1.0. Inicio de sesión

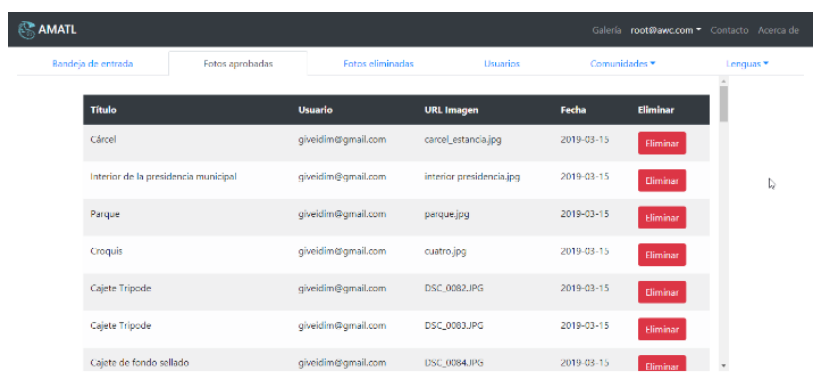

Figura 9 AMATL v2.0. Bandeja de entrada LÓPEZ-ANTONIO, Gilberto, SABINO-MOXO, Beatriz Adriana y MARQUEZ-DOMINGUEZ, José Alberto. AMATL: Galería Colaborativa para la conservación y difusión de fotografías digitales de Teotitlán de Flores Magón, Oaxaca. Revista de Tecnología Informática. 2019 
Despliegue. Como ya se ha mencionado antes, se realizaron dos iteraciones del proceso evolutivo. La segunda versión con la que se cuenta es mucho mejor que la anterior. Gracias a las pruebas que se realizaron se pudo determinar una segunda iteración. A continuación, se presentan las pruebas realizadas.

\section{Pruebas de unidad}

Se realizaron pruebas de hebra ya que el software fue implementado usando el paradigma Orientado a Objetos.

Esto quiere decir que cada instancia de clase encapsula los atributos y métodos que manipulan a una clase. Cada hebra se integra y se prueba de manera individual. Por lo que es el foco de una prueba de Unidad.

Además de la prueba de hebra se realizó la prueba basada en uso, en la que se tuvieron que implementar y probar las clases independientes primero y después las clases dependientes.

\section{Pruebas de validación}

Una vez que se llevaron a cabo las pruebas de integración, se realizaron las pruebas de validación en la que se evaluó cada módulo del sistema. Probando todas las acciones visibles y salidas reconocibles para el usuario, que se mencionan a continuación:

\section{Usuarios en general:}

- Consultar las imágenes de la galería.

Usuario administrador:

- Iniciar sesión.

- Aprobar o rechazar fotografías.

- Dar de alta lenguas maternas.

- Bloquear usuarios.

Usuario colaborador:

- $\quad$ Iniciar sesión.

- Subir fotografías.

- Hacer comentarios.

- Indicar me gusta.

- Compartir en redes sociales.

\section{Prueba alfa}

En esta fase de pruebas se tomó un grupo de usuarios finales que interactuaron con AMATL en un ambiente natural. Con esto se pudieron registrar los errores y problemas de uso que surgieron con cada uno de los usuarios, así como observaciones que dichos usuarios aportaron.

En la Figura 10, 11 y 12 se muestra la evidencia de algunas de las pruebas que fueron realizadas, en distintos ambientes.

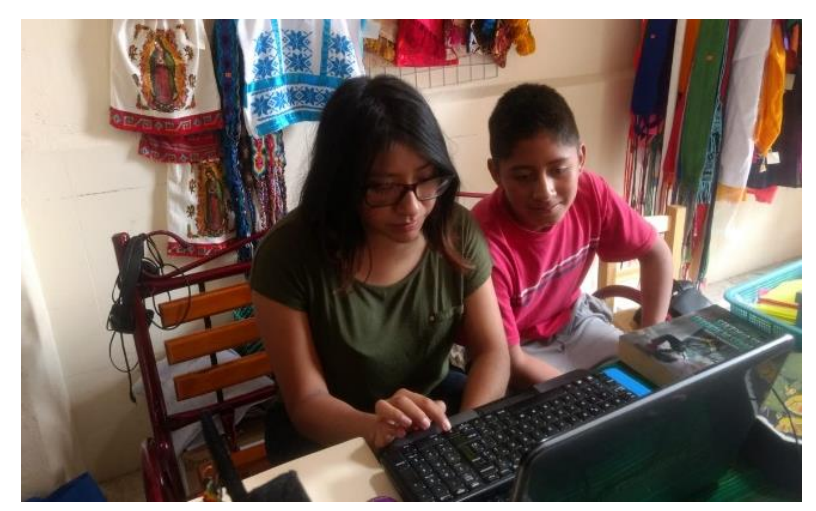

Figura 10 Fase de pruebas en un ambiente natural

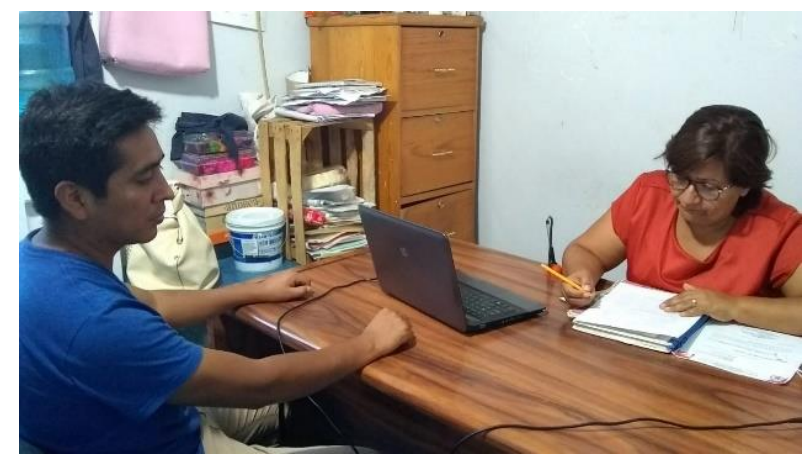

Figura 11 Fase de pruebas en un ambiente natural

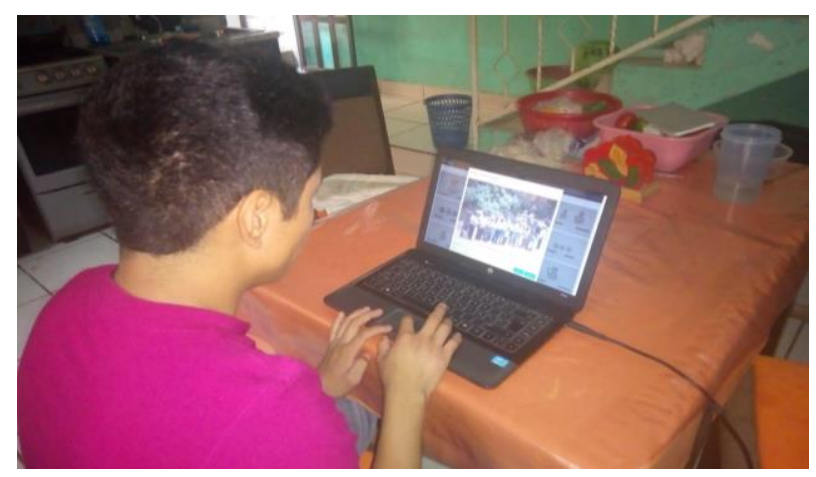

Figura 12 Fase de pruebas en un ambiente natural

\section{Resultados}

Los resultados (Gráfica 1) que fueron obtenidos en la fase de pruebas alfa, corresponden a una muestra de 7 personas a las que se le presentó el software (AMATL) en un ambiente natural.

LÓPEZ-ANTONIO, Gilberto, SABINO-MOXO, Beatriz Adriana y MARQUEZ-DOMINGUEZ, José Alberto. AMATL: Galería Colaborativa para la conservación y difusión de fotografías digitales de Teotitlán de Flores Magón, Oaxaca. Revista de Tecnología Informática. 2019 
Se llevaron a cabo todas las posibles interacciones entre el sistema y el usuario final. En base a un cuestionario cuyo objetivo fue determinar si se cumple con el propósito de AMATL se pudo obtener lo siguiente:

- $\quad$ El 100\% de los usuarios estuvieron satisfechos con AMATL, además que seguirán usando la aplicación y la recomendarían a un amigo.

El $100 \%$ de los usuarios mencionaron que están de acuerdo con el formato de contenido, es decir, tipo y tamaño de fuente, el uso de colores y disposición de los elementos.

- $\quad$ El $100 \%$ consideraron que la calidad de las imágenes es buena y que la navegación dentro de AMATL es fácil. También que las acciones que solicita la aplicación son fáciles de ejecutar y que la cantidad de elementos que se manejan no es excesiva.

El $85.71 \%$ se convencieron de que AMATL permite dar a conocer $y$ difundir información de interés común. Así como, conservar parte las tradiciones, costumbres y momentos históricos de esta localidad mediante la recolección y almacenamiento de fotografías digitales. Y que estas no se ven afectadas por cuestiones ambientales.

\section{Resultados}

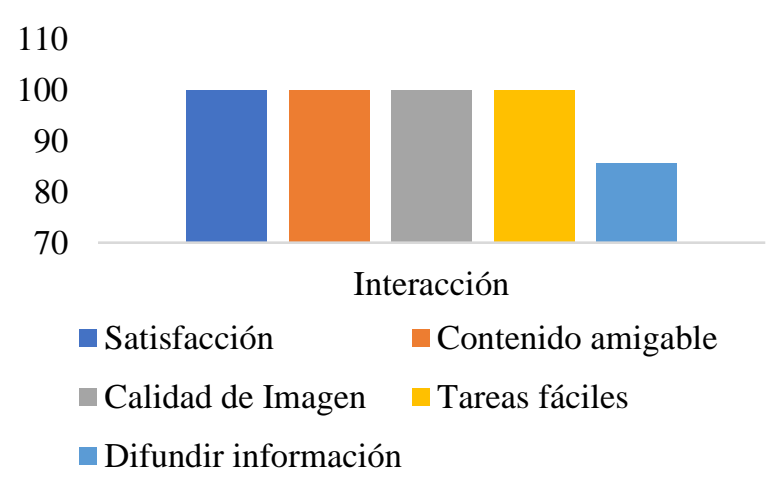

Gráfica 1 Resultados de la interacción con AMATL

Los resultados obtenidos de las pruebas a varios usuarios describen que AMATL es satisfactorio para ellos, y que las tareas solicitadas fueron fáciles de realizar en tiempo y forma.

\section{Agradecimientos}

El contenido y retroalimentación de la galería colaborativa AMATL fue posible gracias a la participación de las autoridades de Casa de la Cultura de la localidad de Teotitlán de Flores Magón y los habitantes de la misma, quiénes son lo que compartieron sus fotografías.

\section{Conclusiones}

La galería colaborativa es un software que permite crear colecciones fotográficas a través de la participación de gente y su colaboración para digitalizar las fotografías y ponerlas en el sistema.

Las pruebas realizadas permiten obtener retroalimentación por parte de los usuarios y mejorar el prototipo, con los resultados obtenidos es posible seguir trabajando para mejorar la facilidad de uso de dicha aplicación. Hasta la fecha se tienen muy pocas fotografías, por lo que es importante continuar difundiendo el software a más gente y seguir construyendo colecciones fotográficas a través de las personas.

\section{Referencias}

García-Fernández J., Fernández-Gavira J., Durán-Muñoz J., Vélez-Colón L. (2015). La actividad en las redes sociales: Un estudio de caso en la industria del Fitness. Retos. Nuevas tendencias en Educación Física, Deporte y Recreación, no. 28.

Hernández, S., Fernández, C., \& Baptista, M. (2014). Metodología de la Investigación. México: McGraw-Hill.

Iglésias, D. (2003). La Gestión de la Imagen Digital. Universitat Pompeu Fabra, Master de Documentación Digital.

Muñoz-Castaño, J. (2001). Bancos de imágenes: evaluación y análisis de los mecanismos de recuperación de imágenes. El profesional de la información, 2001, vol. 10, n. 3, pp. 4-18.

NMX-R-069-SCFI-2016, N. M. (2016). Documentos Fotográficos - Lineamientos para su catalogación. Secretaría de Economía: Dirección General de Normas.

Pressman, R. (2010). Ingeniería del Software: Un enfoque práctico. México: Mc Graw Hill.

LÓPEZ-ANTONIO, Gilberto, SABINO-MOXO, Beatriz Adriana y MARQUEZ-DOMINGUEZ, José Alberto. AMATL: Galería Colaborativa para la conservación y difusión de fotografías digitales de Teotitlán de Flores Magón, Oaxaca. Revista de Tecnología Informática. 2019 